\title{
AMENDMENTS
}

\section{Author Correction: Direct benefits and evolutionary transitions to complex societies}

Cody J. Dey, Constance M. O'Connor, Holly Wilkinson, Susanne Shultz, Sigal Balshine and John L. Fitzpatrick

Correction to: Nature Ecology and Evolution https://doi.org/10.1038/s41559-017-0137, published online 18 April 2017.

In the version of this Article originally published, references were missing from the column "Source(s) for mating and parental care system data" in Supplementary Table 1. The following references have now been added to the relevant species: Brichard 1989 has been added to Chalinochromis popelini, Chalinochromis brichardi and Julidochromis dickfeldi; Clabaut et al. 2007 to Altolamprologus calvus and Julidochromis regani; Konings 1998 to Neolamprologus hecqui; and Kuwamura 1997 to Chalinochromis popelini.

Published online: 13 February 2019

https://doi.org/10.1038/s41559-019-0830-5 